\title{
Development and evaluation of a community immersion program during preclinical medical studies: a I5-year experience at the University of Geneva Medical School
}

\author{
This article was published in the following Dove Press journal: \\ Advances in Medical Education and Practice \\ 19 April 2013 \\ Number of times this article has been viewed
}

\section{P Chastonay ${ }^{1,2}$ \\ $\checkmark$ Zesiger' \\ A Klohn' \\ L Soguel $^{3}$ \\ E K Mpinga ${ }^{1,4}$ \\ $\mathrm{NVVu}{ }^{2}$ \\ $L_{\text {Bernheim }}^{5}$}

'Institute of Social and Preventive Medicine, ${ }^{2}$ Unit of Development and Research in Medical Education, University of Geneva, Faculty of Medicine, Geneva, ${ }^{3}$ Nutrition and Dietetics Department, University of Applied Sciences, Geneva, ${ }^{4}$ Swiss School of Public Health, Zurich, ${ }^{5}$ Department of Neurosciences, University of Geneva, Faculty of Medicine, Geneva, Switzerland
Correspondence: Philippe Chastonay Institute of Social and Preventive Medicine, Centre Médical Universitaire, Michel Servet I, CH-I2II Geneva 4, Switzerland

Email philippe.chastonay@unige.ch
Background: Significant changes in medical education have occurred in recent decades because of new challenges in the health sector and new learning theories and practices. This might have contributed to the decision of medical schools throughout the world to adopt community-based learning activities. The community-based learning approach has been promoted and supported by the World Health Organization and has emerged as an efficient learning strategy. The aim of the present paper is to describe the characteristics of a community immersion clerkship for third-year undergraduate medical students, its evolution over 15 years, and an evaluation of its outcomes.

Methods: A review of the literature and consensus meetings with a multidisciplinary group of health professionals were used to define learning objectives and an educational approach when developing the program. Evaluation of the program addressed students' perception, achievement of learning objectives, interactions between students and the community, and educational innovations over the years.

Results: The program and the main learning objectives were defined by consensus meetings among teaching staff and community health workers, which strengthened the community immersion clerkship. Satisfaction, as monitored by a self-administered questionnaire in successive cohorts of students, showed a mean of 4.4 on a five-point scale. Students also mentioned community immersion clerkship as a unique community experience. The learning objectives were reached by a vast majority of students. Behavior evaluation was not assessed per se, but specific testimonies show that students have been marked by their community experience. The evaluation also assessed outcomes such as educational innovations (eg, students teaching other students), new developments in the curriculum (eg, partnership with the University of Applied Health Sciences), and interaction between students and the community (eg, student development of a website for a community health institution).

Conclusion: The community immersion clerkship trains future doctors to respond to the health problems of individuals in their complexity, and strengthens their ability to work with the community.

Keywords: community immersion, community-based learning, community health, medical curriculum

\section{Background}

Significant changes in medical education have occurred over recent decades due to new challenges in the health sector and new learning theories. ${ }^{1}$ The upcoming generation of physicians will be confronted with professional challenges, such as management of complex health problems, care of patients from different cultural backgrounds, 
and the need to work as team players in collaboration with other health professionals. ${ }^{2}$ Indeed, future physicians will be expected to be not only good clinicians, but also to be capable of working in and with the community, collecting epidemiological data, planning health promotion interventions, promoting screening programs, and understanding the communities their patients live in..$^{3,4}$

This might have contributed to the decision of medical schools throughout the world to adopt community-based learning activities, ${ }^{5}$ with some emblematic examples, such as the Washington, Alaska, Montana, and Idaho program in the US, ${ }^{6}$ the early community-oriented training experiences of Finnish medical schools, ${ }^{7}$ and the heavily community-based curriculum of Canal Suez University in rural Egypt. ${ }^{8}$ In fact, community "immersion learning has emerged as a strategy that addresses both educational and societal needs", according to Zink et al. ${ }^{9}$

The community-based learning approach has been further strengthened by the World Health Organization, which defines the social accountability of medical schools as "the obligation to direct education, research and service activities towards addressing priority health concerns of the community". ${ }^{10}$ Demonstrating social accountability in medical education calls for increasing student awareness of community health in its complexity. ${ }^{11}$

From both a public health perspective and an educational perspective, immersion of medical students in the community seems a relevant way to raise awareness of future physicians of the health needs of the community and of the psychosocial dimensions of any health problem. ${ }^{12}$ Indeed, sending medical students out into the community has been reported to have a positive impact on their future community engagement, giving them the opportunity of an early experience. ${ }^{13,14}$

With the initiation of a new six-year integrated problembased undergraduate medical curriculum in 1996, an interdisciplinary longitudinal community health program was introduced and progressively implemented at the Medical School in Geneva. ${ }^{15,16}$ The objective of the paper is to describe the characteristics of one of the teaching activities of the community health program which has been its hallmark and met with remarkable success, ie, the community immersion clerkship, ${ }^{17}$ as well as some community immersion clerkship evaluation data collected over a 15-year period and developments over the years.

\section{Materials and methods}

\section{Time frame and study population}

The data reported corresponds to a 15-year observation period, ie, from spring 1997 to summer 2012. Over the 15-year period, we studied third-year medical students (in their last preclinical year), varying in number between 65 and 140 students a year, joined since 2007 by a small number of nutrition students (5-18 per year) from the University of Applied Health Sciences, giving in total 1407 students.

On a yearly basis, 22-35 health professionals participated as tutors, guiding the students through their community immersion projects. Some of these were community-based professionals, and others were teachers at the University of Applied Health Sciences or from the Medical School. Also, on a yearly basis, $8-10$ health professionals working in grassroots projects at the community level were invited to present their activities to students in seminars. Furthermore, over the years, students visited (and revisited) more than 100 different community health institutions.

\section{Study design}

The course objectives and educational modalities were defined according to various approaches, and several methods of consensus (such as directed brainstorming and visualized discussion) between teachers and public health professionals taking a public health course at the university ${ }^{18,19}$ were adopted. A survey of public health competencies useful to the practitioner was also done, ${ }^{20}$ as was a review of the literature. The implementation process was started within the context of a global curriculum reorganization, adopting problem-based learning and bedside learning as the main educational strategies. ${ }^{21}$

A global evaluation process was adopted for the program. The students' perception of the program was monitored using a closed-response questionnaire on a five-point scale (1, very dissatisfied; 5 , very satisfied). The questionnaire included items such as potential interest in investigating a health problem in its complexity, the potential enrichment in meeting with community health practitioners, and the potential positive experience of writing a report on the overall organization of the program. The students' perception of the program was also monitored by yearly open group discussion. Second, achievement of learning objectives was evaluated by the program directors and teaching staff, according to a global grid integrating recommendations from educators, ${ }^{22}$ a written report (on average 50 pages), an oral presentation of the group work to fellow students (30-minute presentation followed by a 10-minute question session), a poster presentation either on the community health network in charge of the investigated problem or on a specific aspect of the problem, as well as by a self-evaluation questionnaire administered to a selected cohort 
of students. Further, specific outcomes were monitored by the program coordinators over the years.

\section{Results \\ Program development}

The 4-6-week community immersion clerkship is given at the end of the third preclinical year. Students in groups of 3-5 investigate and report on a priority health problem either in Geneva or in another country, which their group has collectively selected and which has been accepted by the program coordinating staff. As a team, the students investigate their selected health problem by getting directly in touch, interviewing, and interacting with various community health institutions or community actors dealing with the problem at large (politicians, opinion leaders, associations, nongovernmental organizations), as well as meeting with concerned patients and families. Eventually, the students have to report on their investigation and findings in front of their peers. Each group of students has a tutor, usually a medical doctor or a social scientist with a public health background.

The community immersion clerkship is part of a larger community health program spanning the 6 years of undergraduate medical training, including community-oriented (epidemiology, occupational health, health economics, and ethics) as well as community-based training activities (such as ambulatory care clerkship, home care visits, and short-term clerkships in "low threshold" community health structures for vulnerable populations). ${ }^{15,16}$

\section{Definition of learning objectives}

The main learning objectives were defined by consensus meetings between teaching staff and community health workers. These professionals came to the conclusion that, at the end of their community immersion clerkship, students should be able to:

- select and plan as a team an investigation in a community setting on a health problem in order to understand the problem in its biopsychosocial complexity

- collect the pertinent public health data and reflect upon them

- collaborate with the network of health institutions and professionals

- produce a written and oral report of the experiences and the health problem investigated.

More specific learning objectives that were adopted are summarized in Table 1. These include classical public health competencies as well as communication competencies and knowledge of basic human rights.

\section{Definition of educational approach}

Consensus was reached between teaching staff and the educational experts of the Unit of Development and Research in Medical Education at the Medical School and the Bachelor (preclinical) Program Committee that the students should:

- be put into an active learning situation, with the assignment being to investigate a given health topic by going into the community, write a report, and give a lecture on their community experience to their peers

- interact with community health workers and community health institutions in order to discover the community health network

- be given some autonomy in their investigation of a health problem and have the opportunity to choose their field of investigation and their team in order to keep motivation alive

- write a report.

\section{Data evaluation}

\section{Evaluation of perception: student satisfaction}

Satisfaction, as monitored by a self-administered evaluation questionnaire in successive cohorts of students was high, with a mean global value of 4.4 and a mean participation

Table I Specific learning objectives of the community immersion clerkship

At the end of the community immersion clerkship students should be able to

- Describe a health problem in its biopsychosocial and cultural dimensions

- Establish the degree of priority of a health problem

- Describe the social and economic health risk related to a health problem

- Describe the functioning of the health services in relation to a given health problem

Furthermore, students should be able to

- Identify the community health network and the way health practitioners interact

- Analyze the role of general practitioners in handling a health problem in its biopsychosocial dimensions

- Identify the inequalities in access to health care of various subpopulations

- Identify the impact of social inequalities on the health of the individual and the community and to consider it in a human rights perspective

Eventually, by the end of the community immersion clerkship students will have

- Worked in a team

- Collected and analyzed health data

- Interacted with community health workers and the community at large

- Written a report on the health problem investigated

- Given an oral presentation on the health problem investigated in front of their peers and a poster presentation on the health network related to the health problem 
rate over the years of $74 \%$. More specifically, students ranked high the fact that community immersion clerkship allowed them to interact with community health practitioners (mean 4.6) and gave them the opportunity to investigate a health problem in its complexity (mean 4.5). Further, they appreciated the opportunity given to make an oral presentation of their work in front of their peers (mean 4.6). Less positively considered were the obligation to write a report (mean 3.7) and the amount of work that was expected (mean 3.8). Through the yearly brainstorming sessions organized (using the SWOT technique), ${ }^{23}$ students' perception of the highlights and pitfalls of the program showed consistency over time (Table 2), and the taste of liberty (getting away from books) and discovery of the community, patients, families, and health professionals were much appreciated. Less enthusiasm was shown for writing the report or attending seminars.

\section{Evaluation of learning: student performance}

Acquisition of learning objectives, as measured by the quality of the written report, oral presentation, and poster presentation was good to very good for over $85 \%$ of students as evaluated by the program directors and teaching staff. When students were asked to self-evaluate the acquisition of competencies during their community immersion clerkship, it appeared that a large majority felt that they had acquired those competencies well (Table 3, data from two successive cohorts comprising 169 students).

Table 2 Strengths and weaknesses of the community immersion clerkship according to students over the years (aggregated data)

\begin{tabular}{ll}
\hline Strengths & Weaknesses \\
Hands-on experience outside & Time constraints \\
of medical school & Access to health \\
Interacting with community health & professionals can be difficult \\
practitioners, patients, and families & Team work and group \\
Investigating a health problem & dynamics can be deleterious \\
in its complexity & \\
$\begin{array}{l}\text { Discovering social and cultural } \\
\text { dimensions of health }\end{array}$ & \\
$\begin{array}{l}\text { Choosing the problem freely } \\
\text { Constituting the team freely }\end{array}$ & \\
$\begin{array}{l}\text { Giving a lecture to peers } \\
\text { Opportunities }\end{array}$ & \\
$\begin{array}{l}\text { Developing a community health } \\
\text { network }\end{array}$ & Threats \\
$\begin{array}{l}\text { Discovering the role of different } \\
\text { health professionals in handling a health }\end{array}$ & The paradox: the clerkship \\
problem and their complementarity & initially looks like a vacation \\
Taking the clerkship in a developing & long term \\
country & Tutorship can at times be a \\
\hline
\end{tabular}

\section{Behavior evaluation}

Behavior evaluation could not be monitored per se. However, testimonies by former students indicate that the community immersion clerkship experience was a crucial one in their preclinical years. A few examples reported elsewhere ${ }^{17}$ are given here as an illustration:

- "Never again shall we consider a mentally retarded child with the same eyes", from a group who worked with children living with a handicap in Geneva

- "This experience helped us to understand that as medical doctors we are expected to play a role in the political debate", from a group who worked on alternative medicines and their reimbursement by social security

- "We were ambivalent: was it good enough to treat the victim (wife) or go after the aggressor (husband)", from a group who worked on honor crimes in India

- "It was a matter of a couple of packs of antibiotics and the mother would have survived: it was terribly hard to accept", from a group who worked on mother and child health in Burkina Faso.

\section{Impact evaluation}

\section{Educational innovations}

In the context of Geneva, the community immersion clerkship was innovative in introducing community-based activities and allowing the students to experience the hands-on approach of getting involved with community health institutions. It was also innovative in integrating community health workers into the teaching staff. Furthermore, it introduced innovative evaluation procedures, because it abandoned traditional multichoice questions in favor of a written report on the health topic investigated, an oral presentation to fellow students, and a poster presentation on the community health network in charge of the health problem investigated. Some of these innovations even had some influence on several other programs of the curriculum, especially elective programs where several courses adopted written reports or oral presentations in front of colleagues as examination procedures.

\section{Curriculum adaptations}

Two major innovations took place over the years. The first was the development of collaboration with the University of Applied Health Sciences in charge of training nurses, dieticians, midwives, physiotherapists, and medical radiology technicians. This allowed creation of multiprofessional groups of students, similar to the teams of health professionals they would have to work with in the future. This experience, now in its seventh year, appears to be positive, with students 
Table 3 Percentages of students who self-reported being able to perform specific clerkship-related competencies 9 months before the clerkship and one month, one year, 2 years, and 3 years afterwards

\begin{tabular}{|c|c|c|c|c|c|}
\hline Competencies related to community immersion clerkship & $\begin{array}{l}n=121 \\
9 \text { months } \\
\text { before } \\
\%\end{array}$ & $\begin{array}{l}n=152 \\
\text { I month } \\
\text { after } \\
\%\end{array}$ & $\begin{array}{l}n=98 \\
\text { I year } \\
\text { after } \\
\%\end{array}$ & $\begin{array}{l}n=72 \\
2 \text { years } \\
\text { after } \\
\%\end{array}$ & $\begin{array}{l}n=68 \\
3 \text { years } \\
\text { after } \\
\%\end{array}$ \\
\hline Investigate a health problem from a biopsychosocial perspective & 32 & 92 & 90 & 90 & 90 \\
\hline Establish the degree of priority of a health problem in a community & 21 & 76 & 80 & 94 & 90 \\
\hline Collect data on a priority health problem in the community & 29 & 94 & 94 & 94 & 87 \\
\hline Describe organization and functioning of community health services & 12 & 74 & 71 & 76 & 80 \\
\hline Describe inequities in access to health services & 25 & 76 & 80 & 76 & 82 \\
\hline Describe socioeconomic health risk factors & 18 & 86 & 85 & 78 & 78 \\
\hline Identify community health actors & 24 & 92 & 88 & 85 & 86 \\
\hline Describe collaboration channels between community health practitioners & 15 & 82 & 78 & 88 & 87 \\
\hline
\end{tabular}

as well as tutors having identified the complementary vision such an approach brings in studying a health problem in its biopsychosocial dimensions. Second, there was the possibility 10 years ago to take a clerkship, which was initially limited at Geneva, in a community health setting abroad. This triggered extraordinary interest among the students, who over the years came up with interesting community health projects around the world. Students must submit a community health project, which might be accepted or not by an ad hoc committee, and the project must also get support from a local community health structure that is in close connection with a Swiss-based association. Over the years, students have investigated health problems and become acquainted with different health systems with different social and cultural contexts in over 35 countries. Student feedback continues to be very positive, eg, "a unique experience, very enriching, that brings you to consider the world differently and that triggers a very personal journey on one's role as a health professional and a world citizen". Examples of topics investigated abroad and also in Geneva are listed in Table 4.

\section{Interactions between students and the community}

Over the 15-year period of observation, while investigating their specific public health problems, students visited several hundred community health structures, local nongovernmental organizations, and international organizations. They also met and interviewed hundreds of patients and their families, as well as community health personnel and political decisionmakers.

Students who took their clerkship in Geneva also organized specific events related to the health topic they were investigating, such as intra-university prevention campaigns against melanoma, promotion of vaccination against hepatitis B, and developing guidelines for prevention of acquired immunodeficiency syndrome among migrant populations. On several occasions, the students' work had a direct influence on decisions made by health authorities, including:

- having investigated the health situation in "radical" squats, they organized "in-betweens", ie, meetings between the squatters and the state health authorities who had "somewhat lost control of the situation", a consequence of these meetings was the improvement of hygiene in the squats

- having worked on alternative and complementary medicines, the students helped to convince the ministry of health to reconsider reimbursement of these medicines by social insurance

- quite often (at least several times a year), community health professionals and institutions informed the course organizers that: they were grateful to the medical school for allowing its students to visit their community health institutions and to explore the health problem they were in charge of in its complexity, including its social dimensions; the students also regularly brought a new perspective to the investigated problem, in part due to their "innocence", which allowed the professionals to reconsider some of their "established attitudes".

Students who took their clerkship abroad were often able to support local community health centers in a very concrete way, such as teaching diabetic patients at a suburban health center in Ecuador, monitoring neonatal complications in a mother and child health center in Nicaragua, teaching basic hygiene (how to brush teeth and wash hands) to children in an orphanage in Vietnam, monitoring nosocomial infections in a community hospital in Mali, and developing a website and a brand for a small nongovernmental organization in Bolivia.

\section{Discussion}

High student satisfaction rates and sustained student enthusiasm, strong faculty commitment, university support, and 
Table 4 Community immersion program: examples of topics studied over the years in Geneva and abroad

\begin{tabular}{|c|c|c|}
\hline Specific topics studied in Geneva & Domains of investigation & Specific topics studied in foreign countries \\
\hline Measles & Infectious diseases & Malaria in Kenya \\
\hline AIDS & & Tuberculosis in Nepal \\
\hline \multirow[t]{4}{*}{ STD } & & AIDS prevention in Gabon \\
\hline & & Chagas disease in Argentina \\
\hline & & AIDS in Bolivia \\
\hline & & Nosocomial infections in Mali \\
\hline Alcohol consumption & Behaviors/lifestyle & Violence against women in India \\
\hline Addiction to illicit drugs & & Addiction to illicit drugs in India \\
\hline \multicolumn{3}{|l|}{ Smoking } \\
\hline \multicolumn{3}{|l|}{ Violence against women } \\
\hline Diabetes & Chronic diseases & Diabetes in rural Benin \\
\hline Obesity & & Blindness in Nicaragua \\
\hline Coronary heart disease & & Epilepsy in Equator \\
\hline Depression & & Leprosy in Nepal \\
\hline \multicolumn{3}{|l|}{ Dementia } \\
\hline \multicolumn{3}{|l|}{ Paraplegia } \\
\hline \multicolumn{3}{|l|}{ Breast cancer } \\
\hline \multicolumn{3}{|l|}{ Lung cancer } \\
\hline Organization of medical emergencies & Organization of the health system & Access to safe birth in Nicaragua \\
\hline Organ transplantation & & Access to retroviral therapy in South Africa \\
\hline Palliative care versus euthanasia & & Expanded program of immunization in Senegal \\
\hline Reimbursement of alternative/complementary medicines & & Prevention of nosocomial infections in Armenia \\
\hline Activity of general practitioners in rural and urban areas & & Access to health care in the Philippines \\
\hline Premature infants & Maternal and child health & Infant malnutrition in Burkina Faso \\
\hline Pregnancies at risk & & Children living with HIV in Thailand \\
\hline Abortion & & Children living with a handicap in Peru \\
\hline \multicolumn{3}{|l|}{ Infertility } \\
\hline \multicolumn{3}{|l|}{ Children living with a handicap } \\
\hline Cystic fibrosis & Congenital disorders & Children with congenital mental retardation in \\
\hline Autism & & Vietnam \\
\hline \multicolumn{3}{|l|}{ Trisomy } \\
\hline Health of detainees & Health of vulnerable populations & Health of street children in Mongolia \\
\hline Health of sex workers & & Health of street children in Argentina \\
\hline Health of refugees & & Health of refugees in Lebanon \\
\hline Health of clandestine workers & & Health of native populations in Australia \\
\hline
\end{tabular}

Abbreviations: AIDS, acquired immune deficiency syndrome; HIV, human immunodeficiency virus; STD, sexually transmitted infection.

good acceptance by community health actors have allowed the community immersion clerkship program to become a highlight of the Geneva problem-based medical curriculum over the past 15 years. The community immersion clerkship program has also strengthened ties between community health institutions and the Medical School, contributing to the latter's social accountability, as discussed in the literature. $^{24}$

The Geneva community immersion clerkship program was conceived of taking into account the community-based education recommendations defined by the World Health Organization ${ }^{25,26}$ and later developed by Kristina et al, ${ }^{27}$ including competencies in prevention and health promotion, identifying factors impacting on health, determining the incidence and prevalence of disease in the community, and collaborating with professionals from other disciplines. A special focus of the
Geneva community immersion clerkship has been to facilitate students in encountering patients and health professionals in their own environment and confronting them with "the complex interplay between physical, psychological, social and environmental factors in health and illness". ${ }^{27}$

As mentioned elsewhere in the literature, ${ }^{28}$ the consensus approach adopted by teachers and partner institutions in developing the program and defining its objectives seemed to facilitate implementation of the program and contribute to tutors' commitment. It probably also strengthened the interaction between the students and community health institutions, thus providing facilitated learning opportunities, as has been reported already. ${ }^{29}$

The evaluation results overall show student high satisfaction with the community immersion clerkship. In fact, the clerkship gets its highest approval ratings in the Geneva 
undergraduate medical curriculum, ${ }^{16}$ with communitybased medical programs being frequently evaluated well by students. ${ }^{30}$ Students mentioned in particular their interactions with community health professionals, and patients and families as being fulfilling, enriching, and stimulating, which has also been mentioned by others. ${ }^{31}$

Globally, the quality of the students' work, in the form of written reports, oral presentations, and poster presentations, met the teachers' expectations and university standards, in part due to the enthusiasm and commitment of students in their community involvement, which has been reported elsewhere. ${ }^{31}$ Further, the students' perception of their competencies seemed to be maintained over the years. Subjective self-reported perception of acquired competencies and high satisfaction with the community experience might stimulate motivation for learning ${ }^{32}$ and orient future medical activities, contributing to the "training of community-responsive physicians". ${ }^{33}$

Although there was no true behavior evaluation, strong testimonies from students regarding their community experience suggest that this early hands-on experience in community settings might represent an important formative process and contribute to development of appropriate attitudes towards their future medical practice. ${ }^{34,35}$

The community immersion clerkship program was quite innovative in its educational approach, at least when compared with local standards, given that it is a unique community immersion experience during the whole curriculum and fosters critical thinking and creativity among students.

There were two major adaptations made to the community immersion clerkship over the years, much in accordance with international recommendations. ${ }^{36}$ First, a "formal partnership" with the University of Applied Health Sciences in charge of training nurses, physiotherapists, midwives, dieticians, and medical radiology technicians was established with the Medical School, which allowed collaborative projects between students, thus mixing students of different professional orientations and preparing them for future multiprofessional teamwork in the health sector, which has been advocated in the past. ${ }^{37}$ Indeed, students showing prior experience with interprofessional education have been demonstrated to report significantly more positive attitudes towards multidisciplinary teamwork. ${ }^{38}$ Second, the option to take the community immersion clerkship abroad fostered much energy and enthusiasm among students. It also gave students the opportunity for intercultural exposure and confronted them with health care at primary health care levels as well as with health issues when resources are scarce; such intercultural experiences might be especially valuable in the long term for medical practitioners in an ever-changing patient population. $^{39}$

The Geneva community immersion clerkship allowed students to interact with community health professionals, patients and their families, and community health decisionmakers, such as politicians, legislators, and leaders, as well as community and nongovernmental organization leaders, thus preparing them to consider themselves as part of a network and as team members charged with the health of both individuals and communities, as recommended. The community immersion clerkship program also allowed hands-on experience with the implementation of real community health projects with the potential to contribute to the health of communities, and has certainly helped students to understand the concepts of public health. ${ }^{40}$

\section{Conclusion}

The community immersion clerkship aims to train future doctors to respond to the health problems of individuals in all their complexity and to strengthen their ability to work with the community in order to promote healthy lifestyles and adequate health services, as well as raising their awareness of the necessity to collaborate with other health professionals. So far, the experience has been positive and the early enthusiasm of students has survived over the years. In the future, the program will need to move forward and seek more community involvement of students, encouraging them to make a commitment to and take leadership of community health projects, especially ones targeting vulnerable subgroups of the population, and thus drawing the Medical School towards more community involvement and more social accountability and responsibility.

\section{Disclosure}

The authors report no conflicts of interest in this work.

\section{References}

1. Irby DM, Wilkerson L. Educational innovations in academic medicine and environmental trends. J Gen Intern Med. 2003;18:370-376.

2. World Health Organization. Doctors for Health: A WHO Global Strategy for Changing Medical Education and Medical Practice for Health for All. Geneva, Switzerland: World Health Organization; 1996.

3. McIntosh S, Block RC, Kapsak G, Pearson TA. Training medical students in community health: a novel required fourth year clerkship at the University of Rochester. Acad Med. 2008;83:357-364.

4. Steiner BD, Pathman DE, Jones B, Williams ES, Riggins T. Primary care physicians' training and their community involvement. Fam Med. 1999;31:257-262.

5. Schmidt HG, Neufeld VR, Nooman ZM, Ogunbode T. Network of community-oriented educational institutions for health sciences. Acad Med. 1991;66:259-263.

6. Schwarz MR. The WAMI program 25 years later. Med Teach. 2004;26: 211-214. 
7. Isokoski M, Kumpusalo E. Inducement for young doctors to choose careers in primary health care? In: Nooman ZH, Schmidt HG, editors. Innovations in Medical Education. An Evaluation of Its Present Status. New York, NY: Springer; 1990.

8. Nooman ZM. Implementation of a community-oriented curriculum: the task and the problems. In: Schmidt HG, Lipkin M, editors. New Directions for Medical Education. Problem-Based Learning and CommunityOriented Medical Education. New York, NY: Springer; 1989.

9. Zink T, Halaas GW, Finstad D, Brooks D. The rural physician associate program: the value of immersion learning for third-year medical students. J Rural Health. 2008;24:353-359.

10. Boelen C, Heck J. Defining and Measuring the Social Accountability of Medical Schools. Geneva, Switzerland: World Health Organization; 1995.

11. Hennen B. Demonstrating social accountability in medical education. CMAJ. 1997;156:365-367.

12. Benor D, Hobfoll S. Important issues in community-oriented medical education. In: Schmidt HG, Lipkin M Jr, editors. New Directions in Medical Education. Problem-Based learning and Community-Oriented Medical Education. Berlin, Germany: Springer; 1989.

13. Boelen C. L'éducation médicale vue par un expert international en santé publique. Medical education as seen by an international expert in public health. Pédagogie Médicale. 2007;8:44-50. French.

14. Littlewood S, Ypinazar V, Margolis S, Scherpbier A, Spencer J, Dornan T. Early practical experience and the social responsiveness of clinical education: systematic review. BMJ. 2005;331:387-391.

15. Chastonay P, Vu NV, Stalder H. Enseignement des dimensions communautaires dans le cadre de la réforme des études de médecine de l'Université de Genève. Teaching community dimensions at the Medical School of the University of Geneva in the context of a curriculum reform. BMS. 2000;81:875-879. French.

16. Chastonay P, Vu NV, Humair JP, Mpinga EK, Bernheim L. Design, implementation and evaluation of a community health training program in an integrated problem-based curriculum: a fifteen-year experience at the University of Geneva Faculty of Medicine. Med Educ Online. 2012;17:16741.

17. Chastonay P, Klohn AM, Soguel L, Kabengele E. Community immersion: the discovery of public health challenges in Geneva and in the world. In Bernheim L, Chastonay P, Perrelet A, Perrier A (Eds). Medical Studies in Geneva. Retrospective and Perspective. Geneva, Switzerland. Editions Médecine and Hygiène. 2011.

18. Chastonay P, Toscani L, Rougemont A. Priority health problems in for Latin Swiss cantons: a basis for the development of a public health training program. Meducs. 1999;11:13-18.

19. Chastonay P, Bastard B. Learning and Teaching public health: the educational experience of the MAS in public health of the University of Geneva. Médecine and Hygiène. Geneva, March 2009.

20. Chastonay P, Guilbert JJ, Rougemont A. Institutional needs in public health: a survey in three French-speaking Swiss cantons and Ticino. Cahiers Medico-Sociaux. 1992;36:45-53.

21. Vu NV, Bader CR, Vassalli JD. The redesigned undergraduate medical curriculum at the University of Geneva. Presented at the 7th Ottawa Conference on Medical Education. In: Scherpbier AJJA, van der Vleuten CPM, editors. Advances in Medical Education. Dordrecht, The Netherlands: Kluver Academic Publishers; 1997.

Advances in Medical Education and Practice

\section{Publish your work in this journal}

Advances in Medical Education and Practice is an international, peerreviewed, open access journal that aims to present and publish research on Medical Education covering medical, dental, nursing and allied healthcare professional education. The journal covers undergraduate education, postgraduate training and continuing medical education
22. McMillan JH. New Directions in Teaching and Learning: Assessing Students'Learning, No 34. San Francisco, CA: Jossey-Bass; 1988.

23. QuikMBA. SWOT analysis. Available from: http://www.quickmba.com/ strategy/swot. Accessed February 17, 2013.

24. Woollard R. Caring for a common future: medical school's social accountability. Med Educ. 2006;40:301-313.

25. World Health Organization. Community-Based Education of Health Personnel (WHO Study Group Report). Geneva, Switzerland: World Health Organization; 1987.

26. Guilbert JJ. The Educational Handbook for Health Personnel. Geneva, Switzerland: World Health Organization; 1992.

27. Kristina TN, Majoor GD, van der Vleuten CPM. Defining generic objectives for CBE in undergraduate medical programs. Med Educ. 2004;38:510-521.

28. Meyers FJ, Weinberger SE, Fitzgibbon JP, Glassroth J, Duffy FD, Clayton CP. Redesigning residency training in internal medicine: consensus report of the alliance for academic internal medicine education design taskforce. Acad Med. 2007;82:1212-1219.

29. Hays R. Community-oriented medical education. J Teach Educ. 2007;23:286-293.

30. Lubetkin EJ, Krachov SK, Storey-Johnson C. The use of questionnaires to assess achievement of course goals in medical students' longitudinal community-based clinical experiences. Acad Med. 1999;74: 1316-1319.

31. Eckensfels EJ. Contemporary medical students' quest for self-fulfilment through community service. Acad Med. 1997;72:1043-1050.

32. Dowell A, Crampton P, Parkin C. The first sunrise: an experience of cultural immersion and community health needs assessment by undergraduate medical students in New Zealand. Med Educ. 2001;35: 242-249.

33. Brill JR, Ohly S, Stearns MA. Training community-responsive physicians. Acad Med. 2002;77:74.

34. Littlewood S, Ysinazar V, Margolis SA, Sherpbier A, Spencer J. Early practical experience and social responsiveness of clinical education: a systematic review. BMJ. 2005;331:387-391.

35. Dornan T, Bundy C. What can experience ad to early medical education. Consensus survey. BMJ. 2004;329:834-837.

36. Frenk J, Chen L, Bhutta ZA, et al. Health professionals for a new century: transforming education to strengthen health systems in an interdependent world. Lancet. 2010;376:1923-1958.

37. Ficarra B. When doctors and nurses work together. Available from: http://healthin30.com/2010/11/when-doctors-and-nurses-work-together/. Accessed October 2, 2012.

38. Curran VR, Sharpe D, Foristall J, Flyn K. Attitudes of health sciences students towards interprofessional teamwork and education. Med Educ. 2007;41:892-896.

39. Godkin M, Savageau J. The effect of medical students' international experiences on attitudes toward serving underserved multicultural populations. Fam Med. 2003;35:273-278.

40. Magill MK, Quinn R, Babitz M, Saffel-Shrier S, Shomaker S.Integrating public health into medical education: community health projects in a primary care preceptorship. Acad Med. 2002;14:1076-1079.

\section{Dovepress}

including emerging trends and innovative models linking education, research, and healthcare services. The manuscript management system is completely online and includes a very quick and fair peer-review system. Visit http://www.dovepress.com/testimonials.php to read real quotes from published authors. 